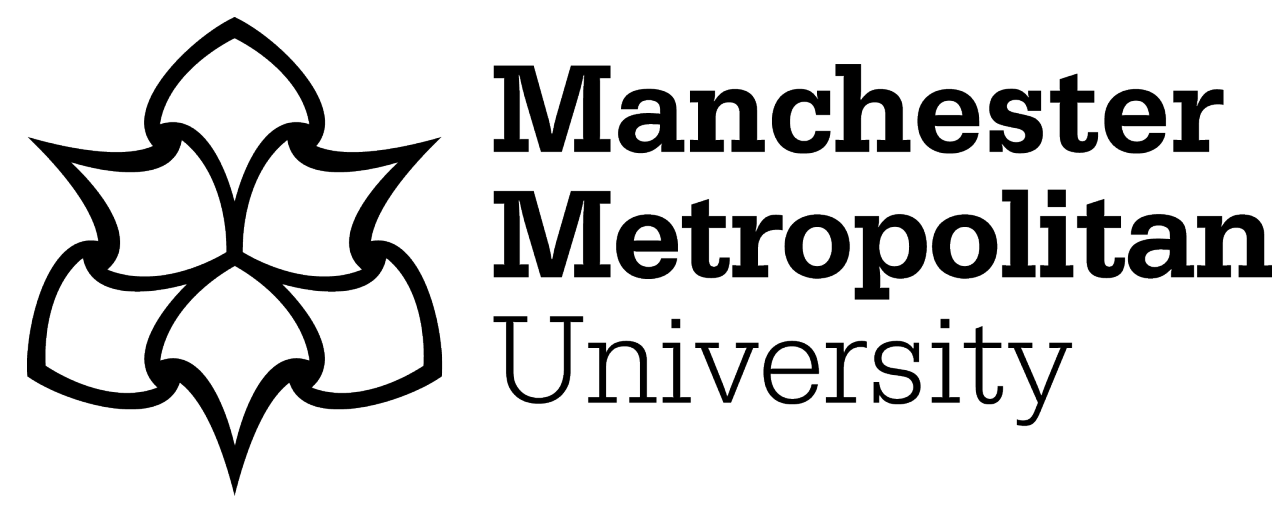

Webb, Lucy (2018) Exploring the characteristics of effective communicators in healthcare. Nursing Standard, 33 (9). pp. 47-51. ISSN 0029-6570

Downloaded from: https://e-space.mmu.ac.uk/621285/

Version: Accepted Version

Publisher: RCN Publishing

DOI: https://doi.org/10.7748/ns.2018.e11157

Please cite the published version 


\title{
Exploring the characteristics of effective communicators in healthcare
}

\author{
Lucy Webb
}

Citation

Webb L (2018) Exploring the characteristics of effective communicators in healthcare. Nursing Standard. doi: 10.7748/ns.2018.e11157

Author details

Lucy Webb, reader and associate professor, Department of Nursing, Manchester Metropolitan University, Manchester, England. Correspondence L.Webb@mmu.ac.uk

Conflict of interest

None declared

\section{Peer review}

This article has been subject to external double-blind peer review and checked for plagiarism using automated software

Accepted

17 April 2018

Published online

$\mathrm{xxx}$

Abstract

Nursing requires strong communication and interpersonal skills to provide effective care, and to ensure that patients, relatives and loved ones have a positive experience of receiving care. The new Nursing and Midwifery Council standards for education and training recognise that nurses are practising in increasingly complex environments and roles. This article identifies the essential communication skills required by nurses in the future, summarising the evidence and theories that comprise the characteristics of a modern nurse communicator. It also suggests approaches that nurses can use to develop their skills.

\section{Keywords}

communication, competence, education, interpersonal skills, non-verbal communication, nursepatient relations, Nursing and Midwifery Council, post-registration education, pre-registration education, professional issues, professional regulation, registration

\section{Introduction}

The Nursing and Midwifery Council's (NMC) new standards for proficiencies for the registered nurse and for nursing education come into force from $28^{\text {th }}$ January, 2019 (NMC, 2018a: 2018b). Both address the knowledge and skills required of practitioners particularly in managerial and public health roles, in an increasingly technological environment. The future 
nurse will need to be emotionally intelligent and resilient and able to respond to multiple and complex care needs but also be at the forefront of a public health role in promoting health and supporting self-care (NMC, 2018c). In addition, they emphasise a need for nurses to possess leadership skills and to deliver and coordinate safe care in multidisciplinary and complex settings and be competent in using digital technology. The standards for communication and relation management are divided into four themes (NMC, 2018d)

- Underpinning communication skills for providing and managing nursing care

- Communication for preventing ill health and supporting self-care

- Communication skills and approaches for providing therapeutic interventions

- Approaches for working with people in professional teams

These new communication standards indicate that future nurses should be able to: manage all forms of communication; establish effective nurse-patient relationships; manage professional boundaries; assess individual and contextual needs; promote healthy behaviours; empower patients and carers to make decisions about their care; provide safeguarding; and work effectively with colleagues and digital healthcare systems. This article examines the key competencies that apply to these themes as being: the underpinning skills, health promotion techniques, responding to information technology. Lastly, the article will look at evidence for strategies for improving communication skills.

\section{The underpinning communication skills}

The standards recognise the underpinning skills to be the foundation of delivering and managing care. They include basic verbal and non-verbal skills, written communication and IT competence.

Evidence from nursing theorists suggests that an effective communicator is someone who has inherent abilities which are developed through education, training and self-reflection enabling them to enter the nursing profession with the ability to empathise - to understand the other's health experience. Nordby (2016) suggested that this skill requires a 'theory of mind'; that is, an ability to appreciate what another person experiences. Nordby also emphasised that theory of mind is essential to provide holistic and patient-centred care. According to Rolfe (2015), training and exposure to caring should develop the nurse's ability to 'care about' rather than 'care for'. Rolfe (2015) differentiated 'caring about' and 'caring for' as holistic care versus task-oriented care and defines Gadamer's 'therapeutic dialogue' (Gadamer 1996) as attentiveness, understanding of the other's needs and ability to respond. These fundamental skills could be categorised as the ability to listen to the patient, empathise with them and communicate that we understand. Therefore, basic communication skills of active listening and empathetic responding underpin an effective nurse-patient relationship.

The nurses' ability to empathise should be underpinned by the essential skills of communication that facilitate effective exchange of information and develop therapeutic relationships in the healthcare context. These competencies include: active listening; verbal communication skills such as attending, focusing and asking questions; and non-verbal communication skills, such as reading body language, understanding proxemics (personal space) and using appropriate eye contact. In addition, nurses are required to be able to identify patients' specific communication needs, such as when to use jargon-free or ageappropriate language, facilitate interpreters (Miller and Webb 2011) or augmented and alternative communication such as sign language or visual aids (Handberg and Voss 2018).

\section{Relationship management}

The process of establishing and maintaining a person-centred relationship needs to be based on mutual respect and trust. Therefore, many models of person-centred relating are underpinned by humanistic approaches. According to Miller and Nambiar-Greenwood (2011), this approach is aided by adopting Rogers' (1961) person-centred therapeutic approach, which should adopt three core conditions (Box 1). 


\section{Box 1. Rogers' three core conditions of client-centred therapy}

- Warmth and genuineness - having an authentic interest in the person and their story. The nurse cannot 'pretend' to care about the person

- Empathy - being able to relate to the person's experience. Understanding their experience but not necessarily agreeing with it

- Unconditional positive regard - accepting the validity and value of the person's experience

(Rogers 1961)

It is no accident that person-centred principles are embedded in a range of therapeutic communication such as counselling, motivational interviewing, brief intervention and assessment interview techniques because this enhances the effectiveness of talking therapies. However, these principles can underpin all communication between nurses and patients, nursing students, relatives and colleagues.

To structure the nurse-patient relationship, it is necessary to understand its stages and its boundaries. Peplau's (1997) model is a well-known illustration of the phases of the nurse-patient relationship (Table 1). According to Peplau (1997), the nurse is initially a stranger in the orientation phase, then a support and enabler, moving the patient from a dependent position to a stage when they are ready to move on independently.

Table 1. Peplau's phases of the nurse-patient relationship

\begin{tabular}{|l|l|l|}
\hline Phase & For the patient & For the nurse \\
\hline 1. Orientation & $\begin{array}{c}\text { Seeks professional assistance and } \\
\text { support }\end{array}$ & $\begin{array}{c}\text { Establishes a rapport with the patient and assists them } \\
\text { to invest in the relationship }\end{array}$ \\
\hline 2. Identification & $\begin{array}{c}\text { Uses the nurse to explore the issues } \\
\text { they experience }\end{array}$ & $\begin{array}{c}\text { Encourages the patient to identify relevant issues. Acts } \\
\text { as a resource for access to help or information }\end{array}$ \\
\hline 3. Exploitation & $\begin{array}{c}\text { Makes use of the nurse to problem- } \\
\text { solve }\end{array}$ & $\begin{array}{c}\text { Develops the patient's competencies and facilitates } \\
\text { recovery }\end{array}$ \\
\hline 4. Resolution & $\begin{array}{c}\text { Becomes free of need for assistance } \\
\text { and support }\end{array}$ & $\begin{array}{c}\text { Facilitates independence and self-care. Facilitates } \\
\text { withdrawal of the relationship }\end{array}$ \\
\hline (Peplau 1997) & \multicolumn{2}{|l}{} \\
\hline
\end{tabular}

Peplau (1997) illustrated the role of the nurse and demonstrated the professional boundaries of what the nurse is there for and not there for; note the emphasis on encouraging self-help and reduction of dependence in the model. The NMC Essential Skills Cluster for communication reiterates this principle in that the registered nurse: 'Initiates, maintains and closes professional relationships with service users and carers (NMC, 2010, p4) Therefore, an effective communicator understands which behaviours support the development of a therapeutic nurse-patient relationship based on trust and mutuality, and which behaviours can threaten the relationship, for example becoming too friendly and over-familiar with patients.

\section{Communication skills for health promotion and self-care}

Modern Western healthcare is challenged more by long-term conditions than acute illnesses, so it is important that healthcare practitioners support people to live with and manage long-term conditions and adopt lifestyles that protect against chronic illness. People with long-term conditions, such as diabetes mellitus, heart disease, chronic obstructive pulmonary disease and severe mental illness, are the most frequent users of healthcare services, accounting for $\mathbf{7 0 \%}$ of costs for health and social care (Department of Health 2015) The Royal College of Nursing (RCN) (2018) stated that nurses have a major role in 
supporting patients to achieve healthy lifestyles and in providing education to optimise their self-care and self-management of long-term conditions.

The new NMC standards for preregistration nursing education expect nurses to be at the forefront of public health to educate and provide motivational support to the public. Consequently, modern communication skills extend to the provision of health education and supporting behaviour or lifestyle changes. The Making Every Contact Count initiative (Public Health England (PHE) 2016) in England, and similar initiatives in other UK countries, enlists nurses as front-line health promoters and behaviour change agents. An RCN survey that examined nurses' role in public health suggested that nurses are in an effective position to provide health promotion holistically, since they have local knowledge of the communities they work within (RCN 2016). Health promotion skills for nurses include being able to deploy generic and specific communication skills such as brief intervention and motivational interviewing for smoking cessation or healthy eating. For nurses in mental health these skills will include motivational interviewing cognitive behavioural approachesHowever, all nurses should be able to use communication skills to screen and assess for lifestyle behaviours that impact on a patient's health provide meaningful health education and advocate for patients (PHE 2013).

\section{Responding to information technology}

Healthcare practitioners write confidential information in patients' medical records every day and share them with other practitioners on a 'need-to-know' basis. Paper and electronic records are often the means by which nurses communicate with other healthcare practitioners about patients, keep a log of care and treatment and maintain an auditable history of the patient. Nursing and medical notes are legal documents and therefore should be complete, factual, accurate and written in plain language (Information Governance Alliance 2016). Handwritten notes should be readable and exclude subjectivity and abbreviations (Gladwin 2011). Increasingly, patients' medical notes are becoming electronic and systematised, which aids the collation of information from multiple sources. A single episode of care for a patient can generate volumes of information from multiple sources. An example of this is shown in Figure 1.

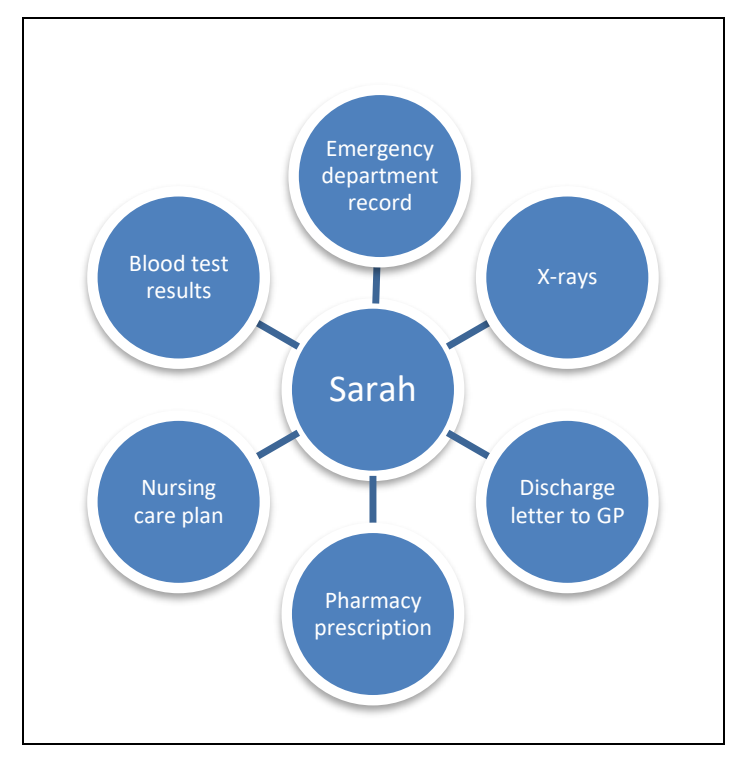

Figure 1. Sources of information for one patient hospital admission

The use of electronic patient records has improved communication between healthcare practitioners and improved patient safety, reducing unnecessary interventions and the time it takes to manage an episode of care (Manca, 2015). However, the use of such systems may also present a threat to patient confidentiality, since healthcare practitioners have access to large amounts of clinical information about patients. One survey found that over $50 \%$ of hospital nurses found their smartphone to be useful in helping them to perform clinical duties for example using text messaging and mobile phone applications to exchange 
information about clinical issues with their colleagues (Mobasheri et al 2015). This poses a threat to confidentiality because these devices are not secure.

It is important to recognise that, in the UK, electronic patient records are also subject to the Data Protection Act 2018 and the Freedom of Information Act 2000, and the associated legal protection in other countries worldwide, so how nurses record patient information must comply with such legislation. The Data Protection Act 2018 stipulates that health records must be, among other standards, justifiable, fair and accurate, up to date and secure. Therefore, what nurses enter into patients' medical records is governed by similar practice standards as the nurse-patient relationship and professional boundaries. The RCN (2012) advised that the primary concern for recording information should be patient care and recommended using the acronym 'SAFER' for professional electronic record-keeping (Box 2).

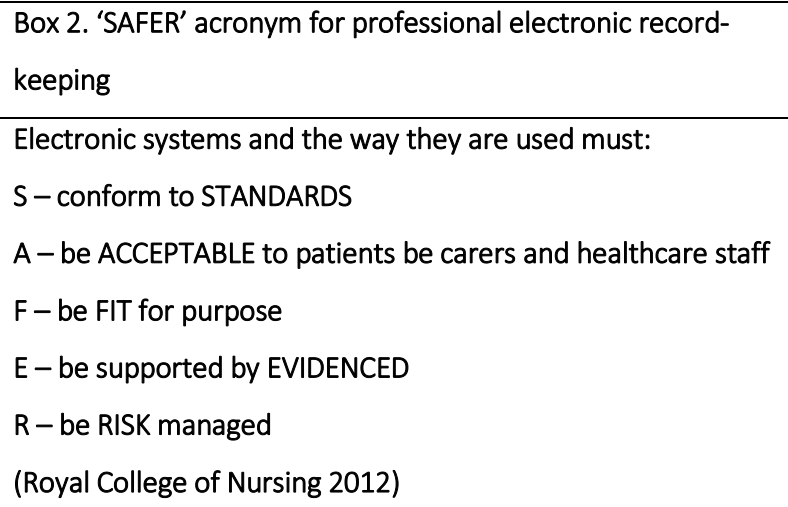

Use of electronic records can improve the effectiveness of healthcare provision, but nurses may need to develop and maintain skills in their use to practise safely and effectively. Gladwin (2011) advised that informatics communication should not reduce the importance of interpersonal skills, which should continue to be the basis of nursing practice and care.

In addition to written and recorded communication with their colleagues, nurses will be expected to take stronger leadership roles in working with professional colleagues. Nurses already have important roles in relation to leadership, such as supervising healthcare staff and students advocating for patients and delegating care. The new standards place increased emphasis on skills related to teamworking, such as conflict management, de-escalation strategies, effective confrontation strategies and managing change. Nurses often have an important role in bridging gaps in communication between medical staff and patients, for example, providing patients with information in jargon-free language. Evidence also indicates that there are continuing gaps in interprofessional communication between, say, nurses and doctors often resulting from different training backgrounds (Tan et al 2017) and different sets of values (Liu et al 2016). As care co-ordinators nurses are in the front-line to ensure that interprofessional communication is effective.

\section{Improving communication skills}

McCluskey et al (2011) undertook a scoping study of healthcare practitioners' views in Scotland, which provided useful indications for practitioners and managers of ways to develop and modernise communication skills in healthcare settings. One of the main findings was that most practitioners prefer to develop their communication skills in the practice setting rather than using formal training in the classroom setting This supports approaches such as reflective practice, guided reflection, role modelling and other forms of in-practice learning that includes self-generated or peer-generated feedback. Approaches such as reflection and clinical supervision are commonly used in nursing, while evidence indicates that self-directed learning is the most effective approach to develop new skills (Fallowfield et al 2002, Heaven et al 2006).

Hamilton and Martin (2007) suggested a framework to improve nurses' interactions with patients, which included the following reflective questions to reflect on practice: 
- What was the purpose of using these skills?

- What was my goal?

- Did I achieve what I set out to achieve?

- What would I do differently?

Hamilton and Martin (2007) suggested that this reflection should focus on the effects of the communication skills that the nurse uses in an episode of patient interaction. This approach could therefore be used for communication skills defined by the NMC, for example with a focus on conveying empathy, using non-verbal skills or promoting behaviour change.

However, evidence from the Scottish study suggests that skills development in communication, especially in the practitionerpatient encounter, requires systematic change and structuring within the workplace to change long-established attitudes to the nursing role. Enhancement of the care culture and willingness to learn comes from changing the ethos of the team, while structuring self-directed learning provides momentum and motivation. Approaches to learning therefore could include selfdirected learning, while adopting a team approach and using formal tools, and formalised feedback, supports whole-team improvement. Suggestions made by peer participants in McCluskey et al's (2011) study included:

- Self-review and reflection tools in checklist format.

- $\quad$ Facilitated scenario work and role-play learning.

- $\quad$ Feedback from patients used as an evidence base for change.

- Peer observation of practice.

- Focus on providing training for generalist and experienced nurses, rather than nurse specialist and trainees.

- Use of technology for self-directed learning, for example DVDs, e-learning and video feedback training.

Therefore, an effective strategy to address communication skills development within teams or specific care settings could be a team approach which is learner-centred. As modelled in McCluskey et al's (2011) study, staff members could identify their needs as a team, and their preferred approaches to learning in practice.

\section{Conclusion}

An effective communicator in current and future nursing practice will have the ability to empathise with patients and carers to ensure that service users feel listened to, understood and supported. They should have the verbal and non-verbal skills required to form a trusting and effective nurse-patient relationship.

Effective communicators will have the ability to engage in a public health role. Knowledge of screening, brief intervention and motivational interviewing and skills in therapeutic interviewing and assessment are essential in providing health promotion and patient education. Traditionally, these may have been regarded as specialist care skills, but are becoming part of generalist healthcare practitioners' communication skills.

Further requirements of an effective communicator will be to have an understanding of the uses of health informatics, the professionalism required to comply with legal frameworks and the ability to be an effective team leader in a stressful environment.

Nurses can develop their communication skills through self-directed learning such as reflection, but fundamental changes in workplace cultures are best supported through a systemic or team approach, supported by management leadership.

Student nurses will have these skills embedded in their training from September 2019. For current practitioners, it may not be enough to rely on existing skills and experience to meet new practice requirement, therefore skills development should be supported for existing staff members to take on these new roles. 
References

Department of Health (2015) 2010 - 2015 Government Policy: long-term health conditions.

https://www.gov.uk/government/publications/2010-to-2015-government-policy-long-term-health-conditions/2010-to-2015-governmentpolicy-long-term-health-conditions (accessed 1.7.18)

Fallowfield L, Jenkins V, Farewell V et al (2002) Efficacy of a Cancer Research UK communication skills training model for oncologists: a randomised controlled trial. Lancet. 359, 9307, 650-656. doi: 10.1016/S0140-6736(02)07810-8.

Gadamer HG (1996) The Enigma of Health: The Art of Healing in a Scientific Age. Polity Press, Cambridge.

Gladwin J (2011) Using health information (informatics). In Webb L (Ed) Nursing: Communication Skills for Practice. Oxford University Press, Oxford, 156-181.

Hamilton S, Martin D (2007) Clinical Development: A Framework for Effective Communication Skills. Nursing Times. www.nursingtimes.net/clinical-archive/leadership/clinical-development-a-framework-for-effective-communicationskills/296359.article (Last accessed: 13 June 2018.)

Handberg C, Voss AK (2018) Implementing augmentative and alternative communication in critical care settings: perspectives of healthcare professionals. Journal of Clinical Nursing. 27, 1-2, 102-114. doi: 10.1111/jocn.13851.

Heaven C, Clegg J, Maguire P (2006) Transfer of communication skills training from workshop to workplace: the impact of clinical supervision. Patient Education and Counselling. 60, 3, 313-325. doi: 10.1016/j.pec.2005.08.008.

Information Governance Alliance (2016) Records Management Code of Practice for Health and Social Care 2016. digital.nhs.uk/dataand-information/looking-after-information/data-security-and-information-governance/codes-of-practice-for-handlinginformation-in-health-and-care/records-management-code-of-practice-for-health-and-social-care-2016 (Last accessed: 13 June 2018.)

Liu W, Gerdtz M, Manias E (2016) Creating opportunities for interdisciplinary collaboration and patient-centred care: how nurses, doctors, pharmacists and patients use communication strategies when managing medications in an acute hospital setting. Journal of Clinical Nursing. 25, 19-20, 2943-2957. doi: 10.1111/jocn.13360.

Manca DP (2015) Do electronic medical records improve quality of care? Yes. Canadian Family Physician Medecin De Famille Canadien. 61, 10, 846-847.

McCluskey S, Heywood S, Fitzgerald N (2011) How Healthcare Professionals in Scotland Develop their Communication Skills, Attitudes and Behaviours. An Independent Report for NHS Education Scotland. www.nes.scot.nhs.uk/media/547484/longterm_conditions-communication-and-human-relationships.pdf (Last accessed: 13 June 2018.)

Miller E, Nambiar-Greenwood G (2011) The nurse-patient relationship. In Webb L (Ed) Nursing: Communication Skills for Practice. Oxford University Press, Oxford, 20-32.

Miller E, Webb L (2011) Active listening and attending: communication skills and the healthcare environment. In Webb L (Ed) Nursing: Communication Skills for Practice. Oxford University Press, Oxford, 52-71.

Mobasheri M, King D, Johnston $M$ et al (2015) The ownership and clinical use of smartphones by doctors and nurses in the UK: a multicentre survey study. BMJ Innovations. 1, 4, 174-181. doi: 10.1136/bmjinnov-2015-000062.

Nordby $H$ (2016) The meaning of illness in nursing practice: a philosophical model of communication and concept possession. Nursing Philosophy. 17, 2, 103-118. doi: 10.1111/nup.12111.

Nursing and Midwifery Council (2018a) Standards for Pre-Registration Nursing Programmes: Part 3 of Realising Professionalism: Standards for Education and Training. https://www.nmc.org.uk/standards/standards-for-nurses/standards-for-pre-registrationnursing-programmes/ (Accessed 1.7.18)

Nursing and Midwifery Council (2018b) Standards of Proficiency for Registered Nurses.

https://www.nmc.org.uk/standards/standards-for-nurses/standards-of-proficiency-for-registered-nurses/ (accessed 1.7.18)

Nursing and Midwifery Council (2018c) Standards for Pre-Registration Nursing Programmes Part 3 of Realising Professionalism: Standards for Education and Training. NMC, London.

Nursing and Midwifery Council (2018d) Future Nurse: Standards of Proficiency for Registered Nurses. New Standards for the Future Nurse. NMC, London. https://www.nmc.org.uk/globalassets/sitedocuments/education-standards/future-nurse-proficiencies.pdf (accessed 1.7.18).

Nursing and Midwifery Council (2010) Essential skills clusters (2010) and guidance for their use (guidance G7.1.5b). Standards for pre-registration nurse education - Annexe 3. NMC, London.

Peplau HE (1997) Peplau's theory of interpersonal relations. Nursing Science Quarterly. 10, 4, 162-167. doi: 10.1177/089431849701000407.

Public Health England (2016) Making Every Contact Count (MECC): Implementation Guide to Support People and Organisations When considering or Reviewing MECC Activity and to Aid Implementation. PHE, London.

Rogers C (1961) On Becoming a Person: A Therapist's View of Psychotherapy. Constable, London.

Rolfe G (2015) Foundations for a human science of nursing: Gadamer, Laing, and the hermeneutics of caring. Nursing Philosophy. 16, 3, 141-152. doi: 10.1111/nup.12075.

Royal College of Nursing (2012) Nursing Content of eHealth Records. www.rcn.org.uk/professional-development/publications/pub003596 (Last accessed: 13 June 2018.) 
Royal College of Nursing (2018) Self Care. www.rcn.org.uk/clinical-topics/public-health/specialist-areas/self-care (Last accessed: 13 June 2018.)

Tan TC, Zhou H, Kelly M (2017) Nurse-physician communication: an integrated review. Journal of Clinical Nursing. 26, 23-24, 39743989. doi: 10.1111/jocn.13832. 